\title{
A qualidade dos serviços prestados pela Universidade Federal de Campina Grande - Campus de Cajazeiras: perspectiva dos discentes
}

\author{
Andreza Pires de Almeida ${ }^{1,2}$ (D) \& Edjane Esmerina Dias da Silva ${ }^{2,3}$ (D)
}

(1) Universidade Federal de Campina Grande, Centro de Formação de Professores, Rua Sérgio Moreira de Figueiredo, Casas Populares, Cajazeiras 58900-000, Paraíba, Brasil. E-mail: andreza.pires@yahoo.com.br

(2) Universidade Federal de Campina Grande, Centro de Ciências Jurídicas e Sociais, Associação Nacional dos Dirigentes das Instituições Federais de Ensino Superior, Programa de Pós-Graduação em Administração Pública, Rua Sinfrônio Nazaré 38, Centro 58800-240, Sousa, Paraíba, Brasil.

(3) Universidade Federal de Campina Grande, Centro de Ciências Jurídicas e Sociais, Unidade Acadêmica de Direito, Rua Sinfrônio Nazaré 38, Centro 58800-240, Sousa, Paraíba, Brasil. E-mail: edjanedias@gmail.com

Almeida A.P. \& Silva E.E.D. (2020) A qualidade dos serviços prestados pela Universidade Federal de Campina Grande - Campus de Cajazeiras: perspectiva dos discentes. Pesquisa e Ensino em Ciências Exatas e da Natureza, 4: e1545. http://dx.doi.org/10.29215/pecen.v4i0.1545

Editor acadêmico: Heydson Henrique Brito da Silva. Recebido: 31 agosto 2020. Aceito: 05 novembro 2020. Publicado: 09 novembro 2020.

Resumo: Os serviços exercem um papel relevante na economia mundial. Dessa forma, encontra-se a educação como um dos serviços ofertados à sociedade, a qual deverá ser prestada pelo Estado sob a regência de princípios tal como a garantia de padrões mínimos de qualidade. O objetivo geral do estudo foi investigar a qualidade dos serviços prestados aos discentes do curso de Licenciatura em Geografia da Universidade Federal de Campina Grande, Campus de Cajazeiras. A pesquisa foi do tipo descritiva e bibliográfica, com abordagem quantitativa. A população e a amostra foi constituída por 120 (cento e vinte) discentes. Os resultados apontaram que os alunos consideraram as cinco dimensões como sendo importantes. A dimensão de Confiabilidade foi considerada a mais relevante comparada as demais dimensões, principalmente, no que tange ao Curso fornecido conforme prometido, quando não houve opinião de insatisfação. Destacou-se ainda, o serviço Matrícula e rematrícula fácil e rápida, quando maioria dos respondentes considerou de Qualidade muito alta. Foi considerada como menos relevante a dimensão Presteza no aspecto Acesso dos discentes às regras e normas da Universidade, que recebeu maiores opiniões dos alunos quanto aos conceitos considerados insatisfatórios para o serviço.

Palavras chave: Ensino superior, confiabilidade, satisfação dos alunos, Modelo SERVQUAL.

The quality of services provided by the Federal University of Campina Grande - Cajazeiras Campus:
students' perspective

Abstract: Services play an important role in the world economy. Thus, education is found as one of the services offered to society, which should be provided by the State under the rule of principles such as the guarantee of minimum quality standards. The aim of the study was to investigate the quality of services provided to students of the Geography Degree course at the Federal University of Campina Grande, Cajazeiras Campus. The research was descriptive and bibliographic, with a quantitative approach. The population and the sample consisted of one hundred and twenty (120) students. The results showed that the students considered the five dimensions to be importante. The Reliability dimension was considered the most relevant compared to the other dimensions, especially with regard to the Course provided as promised, when there was no opinion of dissatisfaction. Also noteworthy was the easy and quick enrollment and re-enrollment service, when most respondents considered very high quality. The Readiness dimension in the aspect Access of students to the University rules and norms was considered as less relevant, which received more opinions from students regarding the concepts considered unsatisfactory for the service. 
Key words: Higher education, reliability, student satisfaction, SERVQUAL Model.

\section{Introdução}

Os serviços exercem um papel relevante na economia mundial. Para Fitzsimmons \& Fitzsimmons (2010) é essencial reconhecer que os serviços são parte integrante da sociedade, estão presentes no cerne da economia e são fundamentais para que esta se mantenha sadia e saudável. Dessa forma, encontra-se a educação como um dos serviços ofertados a sociedade, a qual deverá ser prestada pelo Estado sob a regência de princípios tal como a garantia de padrões mínimos de qualidade (Pereira Filho et al. 2017).

Nos serviços, a avaliação da qualidade surge ao longo do processo de prestação de serviço. A satisfação do cliente com a qualidade do serviço pode ser definida pela comparação de percepção do serviço prestado com as expectativas do serviço desejado (Fitzsimmons \& Fitzsimmons 2010).

Em relação aos serviços prestados pelas Instituições de Ensino Superior (IES), a qualidade é um dos principais fatores que levam os usuários a questionamentos antes de optarem por uma instituição. Nesse sentido, as IES devem prestar serviços com um alto padrão de qualidade, garantindo, assim, a satisfação de seus usuários e a possibilidade de conquistar novos discentes (Milan et al. 2015).

Nesse sentindo, as atitudes positivas em serviços podem levar ao aumento considerável da retenção de usuários, entretanto a desistência ou a perda de um usuário diminui a receita da IES e também pode gerar o enfraquecimento de sua imagem entre os candidatos potenciais (Milan et al. 2015).

Nesse contexto de qualidade dos serviços prestados em educação e de cenário competitivo, as IES precisam estar preparadas para sobreviverem dentro desse ambiente, necessitando cada vez mais investir em qualidade de serviço como uma estratégia de diferenciação, com o desafio de atender aos anseios, necessidades e qualidade consideradas relevantes pelos discentes universitários, buscando conciliar os critérios legais com o aperfeiçoamento constante do processo ensino/aprendizagem.

Portanto, este trabalho parte do pressuposto de que a qualidade dos serviços prestados no ensino superior é de fundamental importância para a permanência do discente no curso, para o desenvolvimento da ciência, seu futuro no mundo do trabalho, para a cidadania e para a vida. Diante disso surgiu o interesse de responder a seguinte questão: Qual o nível de qualidade dos serviços prestados pelo Curso de Licenciatura em Geografia da Universidade Federal de Campina Grande (UFCG), Campus Cajazeiras, na percepção dos próprios discentes?

\section{Instituições de Ensino Superior}

A implementação de universidades no Brasil ocorreu a partir de 1920, quando foi institucionalizada a primeira universidade, localizada no Rio de Janeiro (Fávero 2006). Antes só existiam IES isoladas, como as Faculdades de Direito, criadas em 1827 na capital de Pernambuco e São Paulo. Houve um esforço para organizar e propiciar as condições necessárias para o desenvolvimento de um ensino superior no país a partir da década de 1960, com a federação da IES e criação das universidades federais públicas (Dourado 2009).

Na segunda metade do século passado criou-se condições objetivas para a intensificação da presença da atividade privada no ensino superior e para proliferação das universidades criadas e mantidas pelo Poder Público, financiadas com recursos federais, sob a forma de fundações. Nesse momento, também foram criados os primeiros cursos de pós-graduação, dando-se os primeiros passos para dar às IES não apenas a forma de universidade, mas materialmente essa condição (Sampaio 2014).

Diante dessa expansão, com o objetivo de orientar o ensino, a Lei de Diretrizes e Bases da Educação - LDB (Brasil 1996), mudou de forma significativa a relação do Estado com a educação. Aconteceu a desburocratização para a oferta de vagas no ensino superior e foi 
instalada uma política de acompanhamento e avaliação da qualidade dos serviços educacionais. Esta avaliação realizada pelo Ministério da Educação teve como objetivo a melhoria do desempenho acadêmico do ensino superior (Onusic 2009).

Segundo o Instituto Nacional de Estudos e Pesquisas - INEP (2015), como exemplo dessas avaliações, pode-se citar o Sistema Nacional de Avaliação da Educação Superior (SINAES), que tem como objetivo a regulação dos cursos de graduação no país, com previsão de serem avaliados periodicamente, passando por três tipos de avaliação: para autorização, para reconhecimento e para renovação de reconhecimento.

O SINAES tem como principais objetivos, melhorar o mérito e o valor das instituições, áreas, cursos e programas, nas dimensões de ensino, pesquisa, extensão, gestão e formação; melhorar a qualidade da educação superior e orientar a expansão da oferta, além de promover a responsabilidade social das IES, respeitando a identidade institucional e a autonomia de cada organização (INEP 2015).

Em relação às características das Instituições Públicas de Ensino Superior, no Brasil, apresentam estruturas hierárquicas rígidas, com sistema de carreira baseado no mérito (concursos públicos), com ascensão na carreira de longo prazo e seus processos de trabalho baseados no modelo burocrático, muitas vezes com excessivo apego às normas (Biazzi 2007).

Já as Instituições Privadas de Ensino Superior, de acordo com Kobs \& Reis (2008), apresentam as seguintes características, dentre outras: de competição básica via lançamento de novos cursos, em busca de novas demandas; pouca diferenciação de produtos, em que a diferenciação dá-se no nível da qualidade e das especificações didático pedagógicas.

Conforme a Lei de Diretrizes e Bases da Educação Nacional (Brasil 1996), as IES podem ser públicas ou privadas. As instituições públicas de ensino são aquelas mantidas pelo Poder Público, na forma federal, estadual ou Municipal. Tais instituições são financiadas pelo Estado, e não cobram matrícula ou mensalidade.

Já as IES privadas são administradas por pessoas físicas ou jurídicas de direito privado, com finalidade lucrativa. Ainda, de acordo com a referida lei, a Universidade trata-se de instituição acadêmica pluridisciplinar que conta com produção intelectual institucionalizada, além de apresentar requisitos mínimos de titulação acadêmica. É autônoma para criar cursos e sedes acadêmicas e administrativas, expedir diplomas, fixar currículos e número de vagas, firmar contratos, acordos e convênios, entre outras ações, respeitando as legislações vigentes e a normas constitucionais (Itamaraty 2018).

\section{Serviços}

Os serviços são fundamentais para atividade econômica em qualquer sociedade. $\mathrm{O}$ Estado desempenha papel fundamental no sentido de proporcionar um ambiente estável para investimentos e crescimento econômico. Serviços como educação, saúde, segurança pública, abastecimento de água, conservação de estradas e cuidados com o meio ambiente são essenciais para que a economia de qualquer país sobreviva (Fitzsimmons \& Fitzsimmons 2010). Assim, é imprescindível reconhecer que os serviços são parte integrante da sociedade e não atividades meramente periféricas.

Cabe ressaltar que as IES estão inseridas no contexto das instituições prestadoras de serviços. Os serviços educacionais são reconhecidos como área do setor de serviços. Percebe-se que dos cinco estágios propostos, três são de serviços. O fato é que o setor de serviço vem crescendo rapidamente no Brasil e no mundo, causando com isso uma mudança estrutural na economia mundial (Torres 2011).

Para um melhor entendimento acerca de serviço, cabe destacar alguns conceitos. De acordo com Kotler \& Keller (2012: 382) “...definimos serviço como qualquer ato ou desempenho, essencialmente intangível, que uma parte possa oferecer a outra e que não resulte na propriedade de nada. A execução de um serviço pode ou não estar vinculada a um bem concreto." 
Fitzsimmons \& Fitzsimmons (2010) destacam que uma das características dos serviços é sua intangibilidade diferente dos produtos que são objetos, os serviços são ideias e conceitos, diferente do produto que o cliente pode testar seu desempenho antes da compra, no serviço ele precisará confiar no desempenho da Organização. Conceituam, também, serviço como atividade econômica:

Os serviços são atividades econômicas oferecidas por uma parte a outra, considerando frequentemente desempenhos com base em um período de tempo para provocar resultados desejados nos próprios usuários, em objetos ou em outros bens pelos quais os compradores são responsáveis (Fitzsimmons \& Fitzsimmons 2010: 26).

Conhecer seus clientes traz uma vantagem competitiva para as organizações de serviços, as organizações, devido à natureza do serviço, têm a oportunidade, na maioria das vezes de ter um relacionamento direto com o cliente. Um banco de dados com nomes e endereços dos clientes permite ações diretas de marketing direcionadas e um tratamento individual (Fitzsimmons \& Fitzsimmons 2010).

Os serviços de acordo com Torres (2011) têm um ciclo de vida que é influenciado por alterações ambientais (população, políticas, tecnologia e cultura) e mudanças específicas no público-alvo (clientes, concorrentes). Essas alterações exigem significativas modificações nos serviços e marcam etapas do ciclo de vida de um serviço.

Dessa forma, Kotler et al. (2002) relata que a vida útil de um serviço apresenta quatro estágios, quais sejam: (1) introdução, onde o serviço é apresentado ao mercado ocorrendo um crescimento lento de faturamento; (2) crescimento, com rápida expansão da aceitação pelo mercado e aumento significativo no faturamento; (3) maturidade, marcada pela estagnação da aceitação pelo mercado e estabilização do faturamento e; (4) declínio, período no qual a aceitação e o faturamento apresentam queda acentuada.

\section{Qualidade do serviço}

As exigências a que as organizações estão submetidas aceleraram e fizeram crescer em importância os conhecimentos sobre Gestão da Qualidade, dos quais o Japão foi precursor. Segundo Deming (1990), após a segunda guerra mundial o país estava destruído pela guerra, produzindo produtos com baixa qualidade e custos elevados. Entretanto o país reverteu essa situação tornando-se uma potência mundial e um ícone de produtos de qualidade.

A qualidade é um conceito subjetivo que está relacionado diretamente às percepções de cada indivíduo. Para algumas pessoas representa a satisfação do cliente, para outras, além da satisfação representa também a excelência de um processo (Torres 2011).

São vários os conceitos de qualidade, como afirmam Fitzsimmons \& Fitzsimmons (2010). O termo qualidade não traz uma só conceituação capaz de considerar todas as dimensões que pode alcançar, mas pode estar relacionado com a conformidade entre a expectativa e o resultado atingido. Também, pode-se estar atrelado à percepção do sujeito que exerce a tarefa de julgar ou atribuir níveis de valor a determinada característica ou fenômeno (Hoffmann et al. 2014).

Os serviços muitas vezes são prestados com baixa qualidade, é um fato comum no Brasil e em outros países, tanto no setor público como no setor privado. Em geral, a baixa qualidade provoca no cliente irritação, insatisfação e, muitas vezes, o desejo de procurar outro fornecedor. Para Fitzsimmons \& Fitzsimmons (2010) a satisfação do cliente com a qualidade do serviço pode ser definida pela comparação da percepção do serviço prestado com as expectativas do serviço desejado.

De acordo com Fitzsimmons \& Fitzsimmons (2010) é um desafio medir a qualidade em serviços, pois a satisfação da demanda é determinada por vários fatores intangíveis e características psicológicas, diferente dos produtos com características físicas que podem ser mensuradas de forma objetiva. Ademais, muitas vezes, a qualidade em serviços estende-se além do encontro imediato. 
Nesse sentido, na tentativa de criar uma abordagem padronizada para medir as percepções dos usuários sobre a qualidade de atendimento em serviços, Parasuraman et al. (1988) criaram o modelo SERVQUAL que mede as cinco dimensões da qualidade em serviços: tangibilidade, confiabilidade, presteza, segurança e empatia (Fitzsimmons \& Fitzsimmons 2010).

A ferramenta SERVQUAL é uma escala padronizada de 22 itens divididas em duas etapas, a primeira registra as expectativas dos clientes para uma classe de serviços e a segunda etapa registra as percepções dos clientes sobre uma determinada empresa de serviço (Fitzsimmons \& Fitzsimmons 2010).

Percebe-se então, que essa ferramenta pode ser aplicada a qualquer tipo de organização, desde que adaptadas, conforme as suas peculiaridades na tentativa de ajudar aos usuários, fornecendo-os serviços com qualidade.

\section{Qualidade dos serviços educacionais nas IES}

A busca pela qualidade é fator decisivo em qualquer instituição de ensino, para Milan et al. (2015) a avaliação da qualidade em serviços tem início a partir do primeiro contato com a IES e pode ser decisiva neste momento. Sobretudo, ainda passam pelo rígido controle dos órgãos regulamentadores para que mantenham seu funcionamento, dependendo assim da qualidade do ensino e dos serviços prestados.

De forma estratégica, o Estado cria leis e sistemas que orientam e avaliam o ensino, como forma de garantir a qualidade dos serviços educacionais, como exemplo a Lei de Diretrizes e Bases da Educação - LDB (Brasil 1996) que define e regulamenta o sistema educacional brasileiro, seja ele público ou privado, e o Sistema Nacional de Avaliação da Educação Superior (SINAES) que avalia vários aspectos de ensino, pesquisa, extensão, como a responsabilidade social, o desempenho dos discentes, a gestão da instituição, o corpo docente e as instalações (INEP 2015).

A preocupação com a qualidade no processo educacional traz uma cultura de qualidade, por meio da socialização, participação, interação, integração e trabalho em equipe, comportamentos estes, originários de um processo educacional de qualidade (Torres 2011).

Kotler \& Fox (1994) adverte que somente as atividades acadêmicas não garantem sustentabilidade a longo prazo das IES, e que, os serviços educacionais requerem também a natureza do serviço, pelo conhecimento do relacionamento com os discentes e pela personalização e julgamento da prestação de serviços.

É importante destacar outra característica da IES que diz respeito à temporalidade das relações e o impacto emocional dos relacionamentos neste ambiente, sendo produzido e consumido ao mesmo tempo, ao longo de anos, desempenhando um importante papel nas relações do cotidiano da vida estudantil com as IES, e influenciando a percepção do usuário positivamente ou negativamente (Coutinho 2007).

Nesse contexto, Coutinho (2007: 60) menciona que a avaliação de serviços das IES tem um papel fundamental, ao ser adotada como ferramenta que permite o diagnóstico e o levantamento de ações prioritárias e corretivas de eventuais distorções detectadas, visando a melhoria contínua a partir da percepção dos clientes. Assim, a implementação de ferramentas de avaliação de serviços, através de mecanismos democráticos e transparentes, possibilita à IES ter uma gestão de suas atividades periféricas suplementares mais eficaz, contribuindo para o alcance de seus objetivos institucionais. $\mathrm{O}$ mesmo autor ainda complementa enfatizando que o engajamento de estudantes no processo de avaliação de serviços implica para estes apoderar-se da sua importância, ajudando na contínua construção e reconstrução dessas atividades ao longo do tempo da graduação. O discente ao participar diretamente, assume a parcela de responsabilidade que lhe cabe como membro de uma comunidade educacional.

\section{Metodologia}

O presente estudo foi realizado pelo método de investigação indutivo e adotado um estudo transversal, descritivo, com abordagem quantitativa. No tocante aos objetivos, a pesquisa 
foi classificada como descritiva, do tipo levantamento ou survey e de campo, onde envolveu a interrogação direta das pessoas através de questionário.

Os sujeitos da pesquisa foram constituídos por discentes matriculados no curso de Licenciatura em Geografia do Centro de Formação de Professores (CFP) da Universidade Federal de Campina Grande (UFCG). Segundo dados obtidos junto a coordenação do curso, no ano de 2018, havia um total de 283 (duzentos e oitenta e três) discentes matriculados. A amostra pesquisada foi composta por 120 (cento e vinte) discentes entrevistados em 2018. O critério de inclusão envolveu: o efetivo de discentes matriculados no curso de Licenciatura em Geografia da instituição. Como critérios de exclusão: não estar matriculado no curso de Licenciatura em Geografia, estar ausente no momento da abordagem do questionário e estar afastado das atividades da universidade.

Esta pesquisa obedeceu aos preceitos da Resolução 466/2012 do Conselho Nacional de Saúde, que trata dos princípios da autonomia, não maleficência, justiça e equidade regulamentando os projetos de pesquisa que envolve seres humanos, e submetido ao Comitê de Ética em Pesquisa (CEP) do CFP/UFCG.

Para coleta dos dados utilizou-se um questionário composto de questões fechadas e elaborado tendo por base as dimensões da qualidade em serviços (tangibilidade, confiabilidade, presteza, segurança e empatia) do modelo SERVQUAL de Parasuraman et al. (1991). Para análise do contexto utilizou-se a Escala do Tipo Likert de 05 pontos: (01) Qualidade muito baixa; (02) Qualidade baixa; (03) Qualidade regular; (04) Qualidade alta e (05) Qualidade muito alta, no intuito de caracterizar a importância das variáveis utilizadas para mensurar a percepção dos discentes quanto ao nível de qualidade dos serviços.

Após questionários respondidos, os dados foram agrupados e posteriormente tabulados. Em seguida, os dados foram analisados com o auxílio do programa Microsoft Excel 2010, através da estatística descritiva pela frequência numérica e percentual, sendo através do mesmo elaboradas tabela e figuras para melhor demonstração dos resultados obtidos. Por fim, os resultados foram expostos e discutidos à luz de literaturas pertinentes ao tema.

\section{Resultados e Discussão}

\section{Análise da “tangibilidade” relacionado aos serviços prestados pela UFCG}

Conforme dimensão tangibilidade foram avaliados os aspectos (Curso fornecido conforme prometido, Curso visando beneficiar a sociedade, Curso para o mercado de trabalho, Oportunidades para integração e cooperação entre os alunos e Matrícula e rematrícula fácil e rápida) (Figura 1).

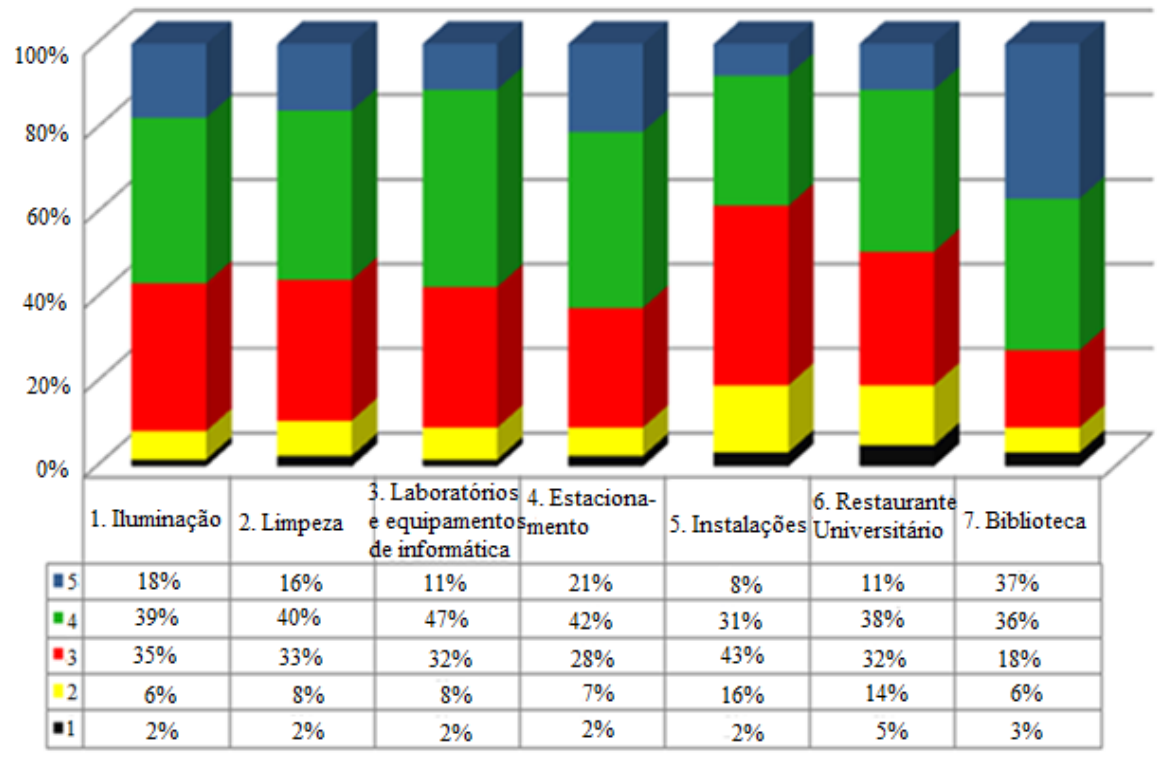

Figura 1. Qualificação dos serviços prestados na UFCG de acordo a “Tangibilidade”. 
Conforme os resultados, percebe-se elevada porcentagem de discentes na percepção do nível de qualidade dos serviços (iluminação, limpeza, laboratórios e equipamento de informática, estacionamento, instalações físicas, restaurante universitário e biblioteca) prestados pelo CFP de Cajazeiras (Figura 1).

Foi conceituado Qualidade alta para todos os serviços, principalmente, nos serviços dos laboratórios e equipamentos de informática afirmado por $47 \%$ dos entrevistados que consideraram os laboratórios estarem bem equipados e modernos, e como Qualidade regular, com exceção da biblioteca, quando apenas $18 \%$ dos graduandos apresentaram a mesma percepção. No serviço Biblioteca, a maioria dos discentes (37\%) demostrou grande satisfação, corroborando com boa parte que apresentou também a mesma percepção de satisfação da qualidade dos serviços prestados no CFP/UFCG, classificando-o como de Qualidade muito alta. Já no quesito instalações físicas, esse mesmo público apresentou nível de satisfação inferior a $10 \%$. Os demais discentes, apesar de se destacarem numa porcentagem menor, mas considerável, não estiveram satisfeitos com os serviços classificando-os como de Qualidade baixa e muito baixa, chamando atenção nos dados percentuais (14\% e 16\%), respectivamente, referindo-se aos discentes que demonstraram menor satisfação, principalmente, nos serviços de instalações físicas e restaurante.

Para os serviços conceituados Qualidade alta e regular, o que pode ter ocorrido foi que, os serviços almejados pela maioria, são tipos de serviços que esperam receber com base na realização das suas necessidades, o que os tornam satisfeitos, ou seja, considera-se aqui que o discente, mesmo sabendo que a instituição nem sempre presta o melhor seviço possível, tem um nível inferior de expectativas para um serviço aceitável (Torres 2011).

Segundo Pelissari et al. (2012) compreender as percepções dos consumidores em relação aos serviços prestados é fundamental para se estreitar laços entre as empresas e instituições prestadoras desses serviços e consumidores. Neste sentido, para os discentes do curso de Licenciatura em Geografia em relação aos serviços prestados pelo CFP/UFCG que se encontram insatisfeitos, é fundamental conhecer suas expectativas para com os serviços a eles ofertados pela instituição, com isso, estreitar laços entre a universidade e discentes visando desempenho adequado do curso.

\section{Análise da "confiabilidade" relacionado aos serviços prestados pela UFCG}

$\mathrm{O}$ critério em questão avaliou aspectos como Curso fornecido conforme prometido, Curso visando beneficiar a sociedade, Curso para o mercado de trabalho, Oportunidades para integração e cooperação entre os alunos e Matrícula e rematrícula fácil e rápida (Figura 2).

Conforme resultados considerados pelos discentes acadêmicos (Figura 2), percebe-se, que a confiabilidade também foi bem avaliada, tendo os seus aspectos (e.g., Curso fornecido conforme prometido, Curso visando beneficiar a sociedade e Curso para o mercado de trabalho, oportunidades para integração e cooperação entre os discentes e da matrícula e rematrícula fácil e rápida) considerados Qualidade alta e muito alta, apresentando percentuais superior aos $50 \%$, como o aspecto "matrícula e rematrícula fácil e rápida". Na situação do serviço ser conceituado de Qualidade alta, implica dizer que os alunos estão satisfeitos, quando os mesmos estão sendo cumpridos dentro dos prazos estipulados. Em resposta para essa situação, Tolfo et al. (2017) entende que existe um esforço conjunto e organização dos colegas do setor para solucionar problemas e atender os questionamentos recebidos dos demais setores, além de enfatizar que existem processos padronizados no setor, o que facilita o fluxo de trabalho, e que os procedimentos são realizados sempre embasados na legislação.

Houve exceção no aspecto "oportunidades para integração e cooperação entre os discentes”, em que foi atribuído percentual elevado (47\%) para Qualidade alta, enquanto apenas $18 \%$ dos discentes atribuíram Qualidade muito alta para o mesmo serviço, tornando esta discrepância percentual mínima de Qualidade muito alta, quando comparada aos demais aspectos, o que pode significar alguma insatisfação por parte dos discentes, haja vista, que houve também classificações Qualidade baixa e muito baixa. 


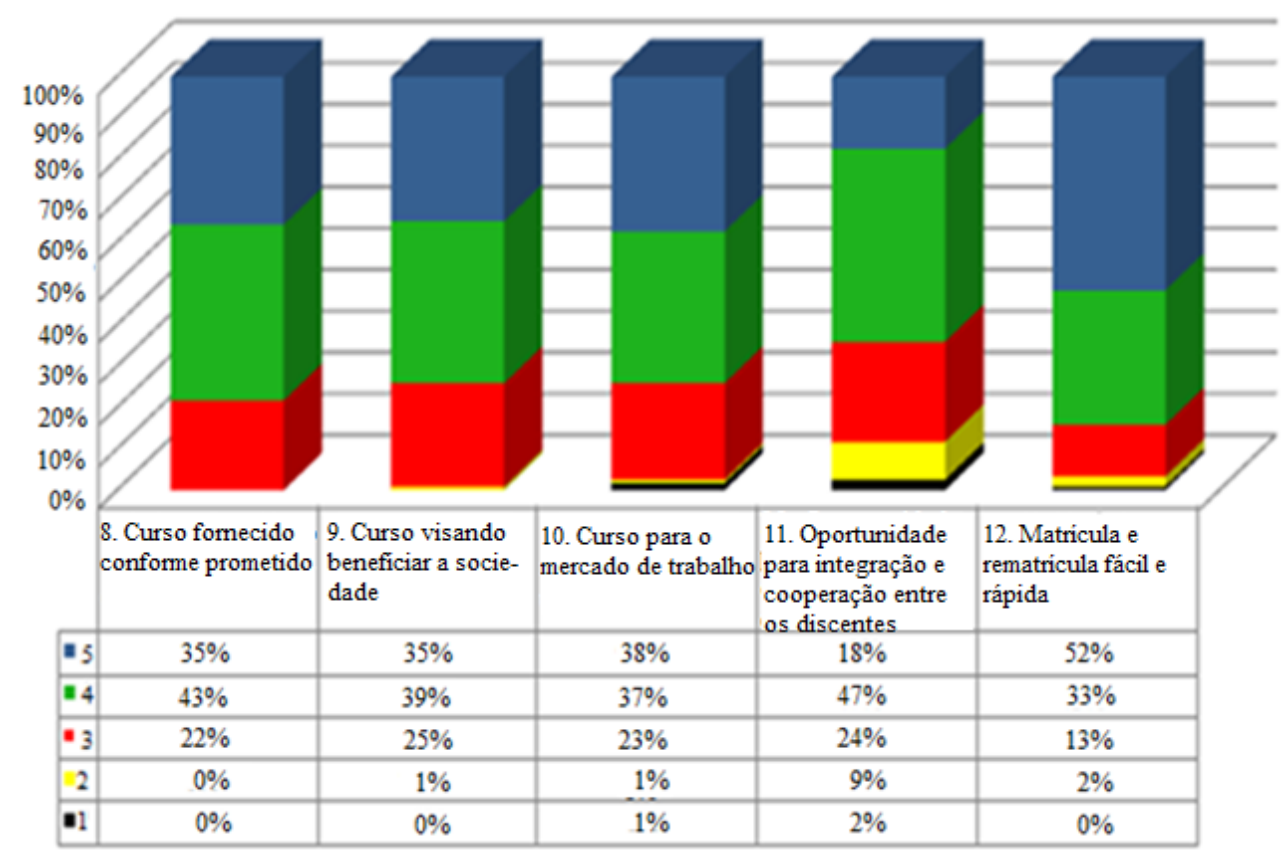

Figura 2. Qualificação dos serviços prestados na UFCG de acordo com a “Confiabilidade”.

Outra parcela dos entrevistados superando os $22 \%$ e chegando aos $24 \%$ considerou ainda Qualidade regular para esses serviços prestados, haja vista, que o aspecto "matrícula e rematrícula fácil e rápida” teve um leve percentual inferior aos $22 \%$ nessa qualificação, se destacando dos demais, mas tornando-se um fato compreensível, haja vista, quando houve maior percepção de Qualidade muito alta, predominado no percentual que é superior a todos os outros serviços. Isso demonstra a qualidade recebida do serviço, fato corroborado por autores quando salientam, na indústria do serviço, que a qualidade proporciona o alcance de vantagem competitiva (Ali et al. 2016).

No cumprimento das promessas de serviço com exatidão, a dimensão confiabilidade foi muito valorizada pelos discentes, principalmente no aspecto "curso fornecido conforme prometido”, mas tendo os cinco aspectos com percentuais superior aos $33 \%$ e ultrapassando os $50 \%$, demonstrando que os serviços prestados no CFP/UFCG são pontos fortes dessa dimensão.

O resultado demonstra uma visão mais crítica dos acadêmicos no que diz respeito ao nível considerado como ideal para os fatores de confiabilidade. Destaca-se que a maioria admite que quando a instituição estudada promete fazer algo em certo tempo, realmente ela faz. $\mathrm{O}$ resultado é esperado e coerente com os aspectos em que, pelo menor conhecimento de causa, pelo nível de expectativas e pelas exigências do discente, é natural que eles tenham uma percepção mais favorável da entidade se comparada a percepção dos acadêmicos (Torres 2011).

\section{Análise da dimensão "presteza" relacionado aos serviços prestados pela UFCG}

Nesta dimensão foram avaliados: Horário de atendimento; Tempo de respostas de solicitações dos discentes perante a coordenação; Homepages atraentes e claras para suporte ao discente; Unidade acadêmica interessada em atender e ajudar ao discente e Acesso dos discentes às regras e normas da Universidade, com respectivas porcentagens de discentes, relacionada a percepção da qualidade desses serviços prestados (Figura 3).

Verifica-se que os resultados foram bastante divergentes nas opiniões para esta dimensão dentro e entre os cinco aspectos. Percebeu-se, que no primeiro aspecto "Horário de atendimento", a maioria das respostas apontou que os serviços foram classificados como Qualidade alta e regular, com percentual de $33 \%$ e $39 \%$, respectivamente. Fato semelhante ao primeiro aspecto também ocorreu aos demais aspectos "Tempo de respostas de solicitações dos alunos perante a coordenação" e "Homepages atraentes e claras para suporte ao discente", quando o percentual de 
opinião dos discentes foi de mesma classificação para a presteza dos serviços. Visto que $18 \%, 22 \%$ e 13\% (respectivamente) dos discentes, para ambos os aspectos, avaliou esse serviço como Qualidade muito alta.

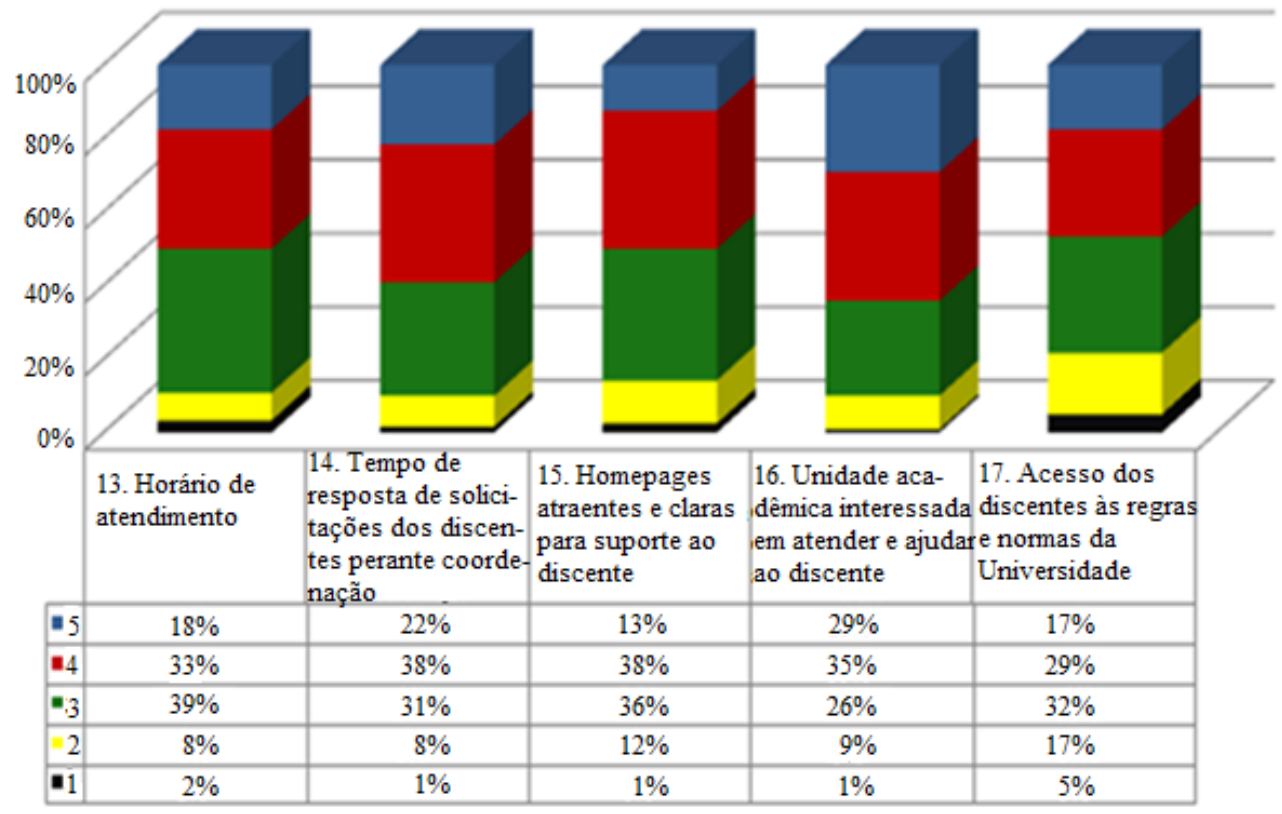

Figura 3. Qualificação dos serviços prestados na UFCG de acordo com a "Presteza".

Os serviços classificados como Qualidade alta e muito alta podem estar relacionados a percepção dos discentes em sentir que o setor solicitado assume seu determinado serviço ou problema a ser resolvido e, ao interagir nesse setor, percebem que o servidor trata com cuidado e disponibilidade para ajudá-los. Nesse contexto, Coutinho (2007) menciona que a avaliação da qualidade dos serviços surge ao longo do processo da prestação dos serviços educacionais. Os serviços considerados de qualidade regular, podem indicar que os acadêmicos ainda percebem alguma dúvida quanto a presteza do serviço, o que pode estar relacionado a resposta da gestão aplicada no serviço, ou seja, falta a qualidade total, caso o servidor demostre insegurança ou até mesmo desinteresse pessoal no serviço, por isso, não havendo qualidade reconhecida como alta entre os discentes. Penna (2011) salienta que tanto no setor privado quanto no público o pessoal resiste à mudança. Existe o medo que a adoção da gestão de qualidade possa diminuir o pessoal $\mathrm{e}$ as oportunidades de promoção, medo da complexidade do trabalho e da falta de adequação às novas responsabilidades, medo do trabalho em grupo, dos processos de decisão com base em dados e relutância em aceitar responsabilidades pelo desempenho.

No aspecto "Unidade acadêmica interessada em atender e ajudar ao discente", apesar do percentual aproximado de respostas insatisfeitas, predominou Qualidade alta, seguido de Qualidade muito alta, o que pode significar a valorização dada pelos discentes aos serviços prestados pela instituição para ajudá-los, suprindo assim, as suas expectativas. Penna (2011) afirma que as expectativas dos clientes são formadas com base em alguns fatores como as suas necessidades, os seus desejos, as suas próprias experiências, a comunicação boca a boca, a comunicação externa e o preço.

Dentro do aspecto "Acesso dos discentes às regras e normas da Universidade", também houve muitas divergências de opiniões. Obteve-se elevado valor de respostas nos serviços qualificados regulares, seguida das respostas para os serviços de qualidade alta. Explica-se, nesse fato, que a qualidade do serviço apresenta várias dimensões, o que torna relativo o conceito dado pelos discentes aos serviços recebidos. Tumino \& Poitevin (2013) relatam que a qualidade do serviço é um fenômeno multidimensional e, em consonância a Grönroos (1984), a avaliação ocorre, basicamente, por duas dimensões: a técnica e a funcional. A primeira representa a 
qualidade dos resultados desejados pelos usuários. Por sua vez, a outra, aponta para a maneira como as interações transcorrem entre prestador de serviço e usuário.

Percebe-se ainda que houve mesma opinião na presteza dos serviços com o mesmo valor (17\%) atribuído como Qualidade muito alta e baixa, discrepância essa que pode indicar que os discentes estão com opiniões divididas quanto ao assunto, uns satifeitos, outros inseguros, quanto ao serviço recebido da instituição que optaram. Segundo Milan et al. (2015), em se tratando dos serviços prestados pelas IES, a qualidade é um dos principais fatores que levam os usuários a questionamentos antes de optarem por uma instituição e/ou curso.

\section{Análise da dimensão "segurança" relacionado aos serviços prestados pela UFCG}

Investigou-se sete aspectos de segurança (Avaliação realizada pelos professores, Apresentação de conteúdo e aulas pelo professor, Método didático de ensino, Professor que conhece a realidade de seus discentes, Forma de avaliação do aprendizado adequada ao curso, Segurança interna da universidade e Professores com formação adequada à disciplina) (Figura 4).

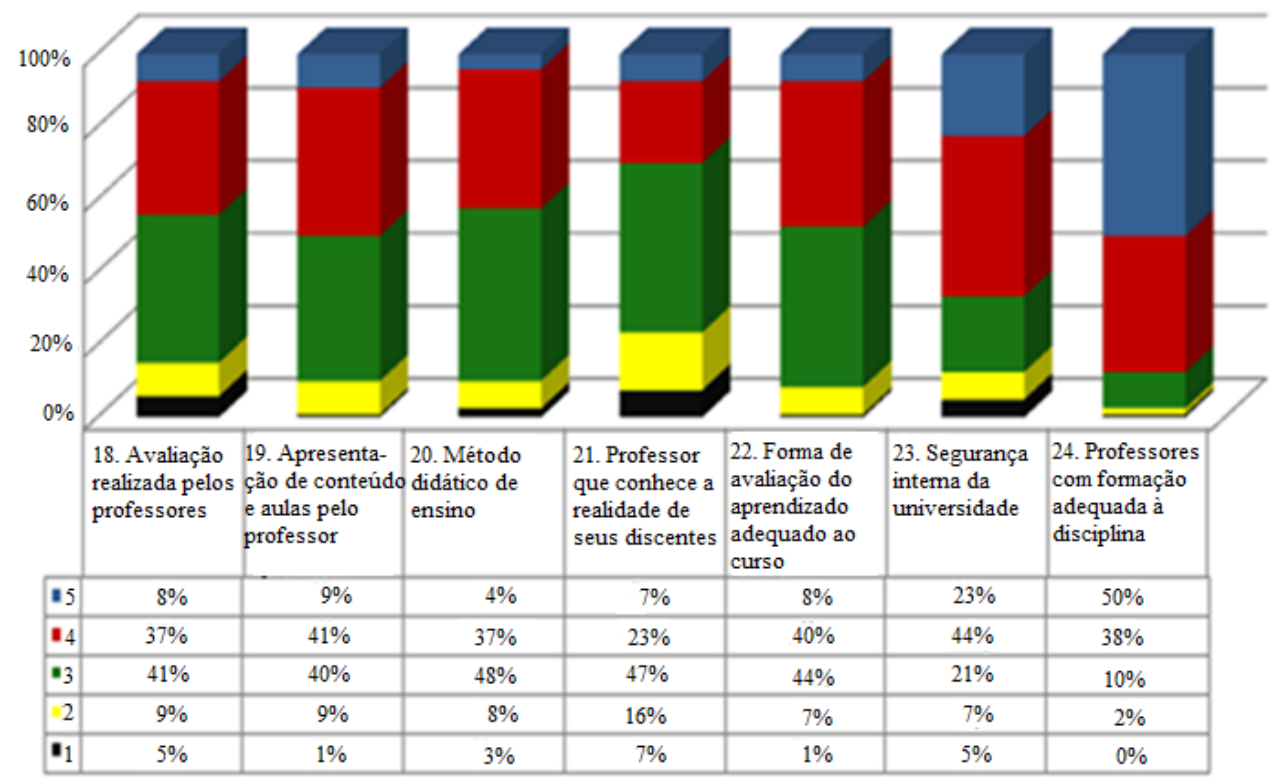

Figura 4. Qualificação dos serviços prestados na UFCG de acordo com a "Segurança”.

Os resultados foram bastante variados, o que pode significar opiniões diversificadas dos discentes para os sete aspectos avaliados na dimensão Segurança. Observa-se, que os aspectos “Avaliação realizada pelos professores”, “Apresentação de conteúdo e aulas pelo professor”, "Método didático de ensino" e "Forma de avaliação do aprendizado adequada ao curso", aparentemente, apresentam o mesmo perfil, pois os maiores valores tiveram conceitos Qualidade alta e regular na opinião dos discentes em relação aos serviços prestados pela UFCG nessa dimensão.

Destacou-se, o serviço "Professores com formação adequada à disciplina" que teve conceitos de Qualidade alta a muito alta chegando aos 50\% na opinião dos discentes, os quais concordaram que os serviços oferecidos pela UFCG/CFP transmitem segurança, ou seja, são seguros, sobretudo no que se refere ao comportamento cordial e a qualificação dos professores. Segundo Hoffman (2010: 387), “a dimensão da segurança diz respeito a competência da instituição, à cortesia que ela dispensa a seus clientes e a segurança de suas operações”. A segurança também reflete a impressão do usuário que se sente em risco, ameaçado ou em dúvida.

Percebe-se então para o mesmo conceito (Qualidade muito alta), que houve uma elevação no percentual de $23 \%$ para o serviço "Segurança interna da universidade". Visto que os demais aspectos de mesmo conceito, estiveram abaixo dos $10 \%$ da opinião dos discentes 
acadêmicos. Fica evidenciado, que os acadêmicos compartilharam de mesma opinião, mesmo em baixo percentual. Pode-se verificar que a legalidade dos atos, os processos padronizados, o fato de que cada servidor tem suas funções definidas de forma clara, a busca constante por cursos de capacitação, a educação e o respeito são pontos cruciais descritos por Tolfo et al. (2017), para que o setor estabeleça segurança aos demais servidores.

Ainda para os serviços citados anteriormente (Segurança interna da universidade e professores com formação adequada à disciplina) no conceito Qualidade regular houve destaque do percentual de respostas de $21 \%$ e $10 \%$, respectivamente, apresentando menores discrepâncias, denotando que os serviços oferecidos estão mais próximos do nível de importância conferido pelos discentes às referidas dimensões, ou seja, os resultados são melhores em relação aos demais que se apresentaram acima dos 40\%, chegando aos 48\%, assumindo assim, que esse serviço ainda precisa de melhorias. Isto apontam uma dificuldade na área de recursos humanos, já que a maioria destes aspectos está relacionada aos empregados (Pelissari et al. 2012).

$\mathrm{O}$ aspecto "Professor que conhece a realidade de seus discentes" foi o único que obteve elevação percentual no conceito Qualidade baixa (16\%), indicando que parte dos discentes não estão totalmente satisfeitos com o serviço. Os estudantes avaliaram esse aspecto como estando fora daquilo que eles esperavam encontrar em um serviço oferecido no setor. As insatisfações apontadas pelos discentes seguem a lógica descrita por Oliver (2010), na qual a satisfação do cliente é vista como uma resposta emocional associada a uma experiência emocional, considerando que o fator psicológico também interfere no julgamento da satisfação e pode permanecer no indivíduo mesmo após a aquisição de um determinado bem ou serviço.

\section{Análise da dimensão "empatia" relacionada aos serviços prestados pela UFCG}

Avaliou-se cinco aspectos (Compreensão e respostas as necessidades e expectativas dos discentes, Professores acessíveis para responder às necessidades dos discentes, Incentivo a produção científica, Receptividade, cordialidade, empenho e prontidão dos técnicosadministrativos e os espaços destinados aos discentes favorecem a integração) (Figura 5).

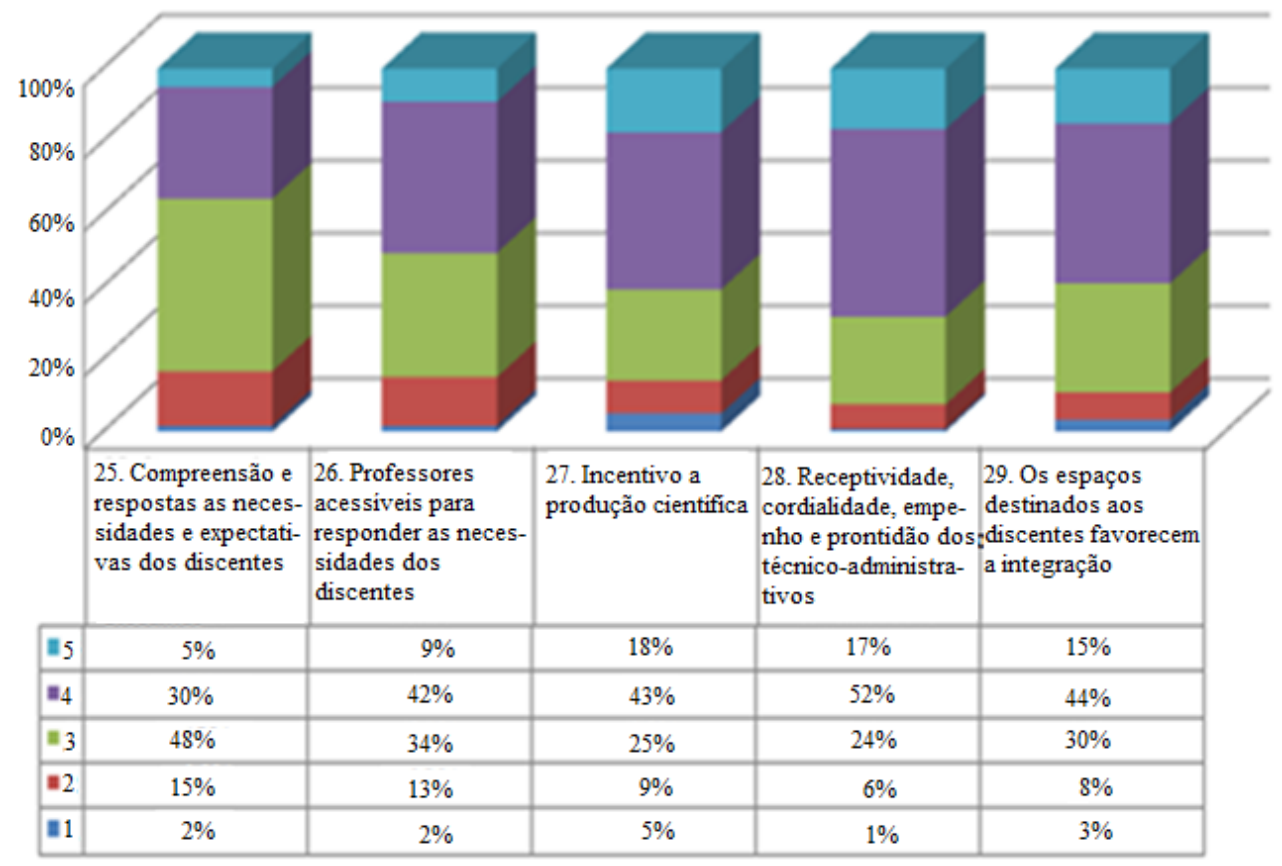

Figura 5. Qualificação dos serviços prestados na UFCG de acordo com a "Empatia”.

Observa-se nos aspectos "Compreensão e respostas as necessidades e expectativas dos discentes", "Professores acessíveis para responder às necessidades dos discentes" e "Os espaços destinados aos discentes favorecem a integração", semelhanças nos dados com maiores 
percentuais nos conceitos Qualidade regular e alta. O Qualidade regular predominou com $48 \%$ de opinião dos acadêmicos, seguido do conceito Qualidade alta no serviço "Compreensão e respostas as necessidades e expectativas dos discentes". A percepção dos entrevistados se diferenciou na visão conceitual, em que maioria classificou o serviço como regular. Ainda é necessário melhoras nesse atendimento, ou seja, a necessidade de tratamento atencioso para termos opiniões ao alcance do conceito qualidade alta ou muito alta para o serviço.

Opiniões referentes aos espaços destinados aos discentes não favorecerem a integração entre os mesmos e professores, recebeu Qualidade regular (30\%), levando também aos conceitos Qualidade baixa e muito baixa. Isto pode estar associado a pontos considerados negativos como, por exemplo, turmas grandes para os espaços dificultando um eficiente modelo de ensinoaprendizagem. Singer-Freeman \& Bastone (2016) mencionaram que a interação entre professores e discentes torna-se mais difícil nas turmas com um elevado número de alunos, prejudicando assim o processo de aprendizagem e aumentando os riscos de evasão nas turmas.

Quanto ao conceito Qualidade muito alta, os aspectos "Compreensão e respostas as necessidades e expectativas dos discentes" e "Professores acessíveis para responder às necessidades dos discentes" apresentaram menores valores (5\% e 9\%), respectivamente, em comparação aos demais aspectos, com opiniões deste conceito acima de $15 \%$. Nessa situação, os discentes perceberam que os resultados das percepções sobressaíram às suas expectativas sobre os serviços, por isso, o resultado se manteve positivo sinalizando que o CFP e seus funcionários prestam serviços de acordo com interesse dos usuários e conhecem as necessidades dos mesmos. Apesar de haver falhas nesse quesito (constatado pelo conceito Qualidade regular), possivelmente, por conta da grande demanda e do quadro de funcionários reduzido (Alves 2017). Os valores referentes a Qualidade baixa dos serviços destacados no contexto, apresentaram-se mais acentuados ( $15 \%$ e $13 \%$, respectivamente), em relação aos demais aspectos.

Houve predomínio do conceito Qualidade alta entre a maioria dos discentes (43\% e 52\%, respectivamente), o que pode indicar que os serviços são prestados de maneira satisfatória, principalmente para aqueles que opinaram por esse conceito, chegando a ultrapassar os $50 \%$ de preferência. Neles há demonstração de interesse e a atenção personalizada com os discentes, incentivando-os na produção científica. Além do mais, o quadro técnico-administrativo é acessível possuindo sensibilidade e esforço para atender às necessidades dos alunos.

No que tange a percepção dos alunos no aspecto receptividade, cordialidade, empenho e prontidão dos técnicos-administrativos, houve atribuições de conceitos Qualidade baixa e muito baixa em pouco mais que $6 \%$. As insatifações podem estar associadas também a reclamações na dimensão "presteza" dos serviços prestados pelos funcionários. Em geral, especula-se que a falta de qualidade provoca irritação, insatisfação e, muitas vezes, o desejo de procurar outra instituição. $\mathrm{O}$ descontentamento, decepção, autopiedade, ansiedade e arrependimento relativos à insatisfação estão relacionados a falhas inerentes aos serviços (Zeithaml et al. 2014).

\section{Conclusões}

Em geral, os resultados consideraram dimensões importantes para avaliar uma universidade demonstrando que os discentes não estão plenamente satisfeitos ou insatisfeitos com a qualidade dos serviços prestados.

Os discentes da UFCG consideraram as cinco dimensões como sendo importantes, sendo a dimensão de "confiabilidade" como a mais relevante, principalmente, no serviço "Curso fornecido conforme prometido", na qual não houve opinião para os conceitos considerados instisfatórios Qualidade baixa e muito baixa, onde também o conceito Qualidade regular se fez reduzido. A dimensão "presteza" no aspecto acesso dos discentes às regras e normas da Universidade" foi considerada menos relevante recebendo maiores opiniões dos discentes quanto aos conceitos considerados insatisfatórios para o serviço.

A pesquisa mostrou que há muitas divergências de opiniões na qualidade dos serviços prestados pelo CFP, no entanto, aos gestores não cabe analisar somente os atributos e as 
dimensões da qualidade dos serviços prestados pela instituição, mas também a possibilidade e o cuidado em avaliar quais as prioridades na percepção dos discentes.

A instituição precisa de instrumentos para avaliar a qualidade de seus serviços, tendo em vista entender as necessidades, desejos, anseios e expectativas dos discentes, bem como compreender o que pode melhorar em seu processo de prestação de serviços. Isto possibilitará atender às expectativas dos discentes e daqueles que irão ao mercado competitivo de bens e serviços em busca de ensino de qualidade.

Vale ressaltar que o índice geral de satisfação pode ser utilizado pela UFCG continuamente pra uma análise da evolução de desempenho nos serviços, principalmente através do método SERVQUAL, o qual permite perceber pontos fortes e fracos, além de certo aperfeiçoamento ao longo do tempo.

\section{Agradecimentos}

As autoras agradecem aos avaliadores pela revisão crítica do manuscrito.

\section{Referências}

Ali F., Zhou Y., Hussain K., Nair P.K. \& Ragavan N.A. (2016) Does higher education service quality effect student satisfaction, image and loyalty? A study of international students in Malaysian public universities. Quality Assurance in Education, 24(1): 70-94. https://doi.org/10.1108/QAE-02-2014-0008

Alves A.C. (2017) A percepção da qualidade na prestação de serviços públicos: estudo de caso de um centro de saúde, na cidade de Campina Grande - Paraíba. Pensamento \& Realidade, 32(4): 74-93.

Biazzi M.R. (2007) Instituições Públicas de Ensino Superior: Estudo de casos e aperfeiçoamento de processos administrativos. Dissertação (Programa de Pós-Graduação em Engenharia). Escola Politécnica, Universidade de São Paulo, São Paulo.

Brasil (1996) Lei de Diretrizes e Bases da Educação Nacional. Lei n. 9.394, de 20 de dezembro de 1996. Brasília: Diário Oficial da União, 23 dezembro de 1996.

Coutinho F.C.C. (2007) Avaliação da qualidade dos serviços de uma instituição de Ensino Superior. Dissertação (Programa de Pós-Graduação em Administração). Escola de Administração, Universidade Federal da Bahia, Salvador, Bahia.

Deming W.E. (1990) Qualidade: A Revolução da Administração. Rio de Janeiro: Saraiva. 368 p.

Dourado L.F. (2009) Políticas e gestão da educação superior: múltiplas regulações (p. 149-167). In: Dourado L.F. (Org.). Políticas e gestão da educação no Brasil: novos marcos regulatórios. São Paulo: Xamã. 191 p.

Fávero M.L.A. (2006) A Universidade no Brasil: das origens à Reforma Universitária de 1968. Educar, 28: 17-36.

Fitzsimmons J.A. \& Fitzsimmons M.J. (2010) Administração de serviços: operações, estratégia e tecnologia da informação. $6^{\circ}$ edição. Porto Alegre: Bookman. 583 p.

Grönroos C. (1984) A service quality model and its marketing implications. European Journal of Marketing, 4(18): 36-44. https://doi.org/10.1108/EUM0000000004784

Hoffman K.D. (2010) Princípios de Marketing de Serviços: conceitos, estratégias e casos. São Paulo: Cengage Learning. 624 p.

Hoffmann C., Zanini R.R., Corrêa Â.C., Siluk J.C.M., Júnior V.F.S. \& Ávila L.V. (2014) O desempenho das universidades brasileiras na perspectiva do Índice Geral de Cursos (IGC). Educação e Pesquisa, 40(3): 651-666. http://dx.doi.org/10.1590/s1517-97022014041491

INEP - Instituto Nacional de Estudos e Pesquisas Educacionais Anísio Teixeira (2015) Sistema Nacional de Avaliação da Educação Superior - SINAES. Disponível em: http://portal.inep.gov.br/sinaes (Acesso em 22/02/2018). 
Itamaraty (2018) Ministério das Relações Exteriores. Divisão de Temas Educacionais: Denominações das Instituições de Ensino Superior (IES). Disponível em: http://www.dce.mre.gov.br/nomenclatura_cursos.html (Acesso em 09/08/2018).

Kobs F.F. \& Reis D.R. (2008) Gestão nas Instituições de Ensino Superior Privadas. Revista Científica de Administração, 10(10): 7-18.

Kotler P. \& Fox K.FA. (1994) Marqueting Estratégico para Instituições Educacionais. São Paulo: Atlas. 448 p.

Kotler P. \& Keller K.L. (2012) Administração de Marketing. 14 edição. São Paulo: Pearson Education do Brasil. 794 p.

Kotler P., Hayes T. \& Bloom P.N. (2002) Marketing de Serviços Profissionais: Estratégias inovadoras para impulsionar sua atividade, sua imagem e seus lucros. $2^{\circ}$ edição. São Paulo: Manole. 511 p.

Milan G.S., Eberle L., Corso A. \& Toni D. (2015) A qualidade em serviços e a satisfação de clientes: comparação entre a percepção de alunos de graduação e de pós-graduação de uma IES. Revista de Administração da UFSM, 8(3): 415-437. http://dx.doi.org/10.5902/198346599935

Oliver R.L. (2010) Satisfaction: a behavioral perspective on the consumer. $2^{\circ}$ edition. New York: The McGraw-Hill. 544 p.

Onusic L.M. (2009) A Qualidade de Serviços de Ensino Superior: o caso de uma instituição de serviço público. Tese (Programa de Pós-Graduação em Administração). Faculdade de Economia Administração e Contabilidade, Universidade de São Paulo, São Paulo, Brasil.

Parasuraman A., Berry L.L. \& Zeithaml V.A. (1991) Refinement and reassessment of the SERVQUAL scale. Journal of Retailing, 67(4): 420-450.

Parasuraman A., Zeithaml V.A. \& Berry L.L. (1988) SERVQUAL: A multiple- Item Scale for measuring consumer perceptions of service quality. Journal of Retailing, 64(1): 12-40.

Pelissari A.S., Solis D.R., Ianagui E.C., Gonzalez I.V.D.P. \& Setubal F.M.R. (2012) Aplicação e Avaliação do Modelo Servqual para Analisar a Qualidade do Serviço. Revista Científica Internacional, 1(1): 1-24. http://dx.doi.org/10.6020/1679-9844/2301

Penna R.F. (2011) A qualidade dos serviços e seu impacto na satisação dos acadêmicos do curso de graduação em Física no ano de 2011. Monografia - Especialização (Programa de pósGraduação em Administração). Universidade Federal de Santa Maria, Santa Maria, Rio Grande do Sul, Brasil.

Pereira Filho E., Tenório F.A.G. \& Silva J.R. (2017) Oportunidades de Melhorias: Qualidade do Serviço Prestado em Escolas Públicas. Revista Iberoamericana sobre Calidad, Eficacia y Cambio em Educación, 15(2): 31-55. http://dx.doi.org/10.15366/reice2017.15.2.002

Sampaio K.R. (2014) A gestão da qualidade nas instituições de ensino superior. Faculdade Cearense em Revista, 8: 1.

Singer-Freeman K. \& Bastone L. (2016) Pedagogical Choices Make Large Classes Fell Small. NILOA Occasional Paper, 27: 1-26.

Tolfo S.D., Roth H.S., Dias V.A. \& Luiz G.C. (2017) Avaliação da qualidade dos serviços do setor financeiro de uma universidade: uma análise comparativa entre a visão dos servidores prestadores e dos servidores usuários dos serviços. Revista Sociais \& Humanas, 30(1): 105123. http://dx.doi.org/0.5902/2317175824825

Torres R.D. (2011) A qualidade dos serviços prestados por uma instituição de ensino superior federal na visão dos vestibulandos e universitários. Dissertação (Programa de Pós-Graduação em Administração). Fundação Pedro Leopoldo, Pedro Leopoldo, Minas Gerais, Brasil.

Tumino M.C. \& Poitevin E.R. (2013) Evaluación de la calidad de servicio universitario desde la percepción de estudiantes y docentes: caso de estudio. Revista Iberoamericana sobre Calidad, Eficacia y Cambio en Educación, 12(2): 63-84.

Zeithaml V.A., Bitner M.J. \& Gremler D.D. (2014) Marketing de serviços: a empresa com foco no cliente. $6^{\circ}$ edição. Porto Alegre: AMGH. 664 p. 